\title{
The Effect of Vacuum Pressure on the Quality of Liquid Palm Sugar Resulting From the Vacuum Evaporation Process
}

\author{
Slamet Wiyono ${ }^{1 *}$, M S Fachry ${ }^{2}$, S Abdullah ${ }^{2}$, Dwi Sidik ${ }^{2}$, Erwin $^{2}$ \\ ${ }^{1}$ Center of Excellence Local Food Innovation Universitas Sultan Ageng Tirtayasa Cilegon, Indonesia \\ ${ }^{2}$ Renewable Energy Design Laboratory, Engineering Faculty Universitas Sultan Ageng Tirtayasa Cilegon, Indonesia \\ "Corresponding author. Email: maswie@ untirta.ac.id
}

\begin{abstract}
Traditional technology is used at the craftsman level, using very simple equipment. The use of simple tools affects the production capacity and quality which is relatively low. From previous research that has been carried out through an internal grant, the vacuum Evaporator process provides a processing method that is proven to reduce the water content of liquid sugar, but because the liquid sap is processed almost 8 hours after the preheating process for 1 hour. Produce products that are still fermenting. This research aims to improve the vacuum evaporator unit and test the unit's performance to produce quality liquid palm sugar according to liquid sucrose standard NO. 8779.2019. The result is Within 9 hours 40 minutes at 0.25 ATM, it reaches $21 \%$ water content, following the liquid sugar standard set by the draft Indonesian liquid sugar standard.
\end{abstract}

\section{Keywords: Evaporation, Liquid Palm Sugar, Vacuum Pressure}

\section{INTRODUCTION}

Previous research carried out through an internal grant of the vacuum Evaporator process provides a processing method proven to reduce the water content of liquid sugar, but because the liquid palm is processed almost 8 hours after the preheating process for 1 hour. Produce products that are still fermenting [1].

So, it is necessary to carry out the process of reducing the water content with a process below the temperature of $100 \mathrm{C}$ with pressure below 1 ATM, immediately after the liquid is taken from the tree. This study aims to see the effect of vacuum pressure on the resulting product.

If the water reduction process is carried out at a high temperature above $140 \mathrm{oC}$, then the Maillard process [2] will occur excessively and cause a bitter taste in palm sugar. Phisut-Naknean's research showed that liquid palm sugar processed with a vacuum stored at a temperature of $4 \mathrm{C}$ and $30 \mathrm{C}$ for 12 months showed a decrease in the quality of palm sugar processed with a pan compared to liquid palm sugar processed with a vacuum [3].
As a quality measure, the effect of vacuum pressure on the processing time in making liquid palm sugar will be seen by removing $75 \%$ of the water content.

Gap Research, Research so far has focused on process technology for large-scale companies, research to showcase technology that can be accessed by home industries is still rare and difficult to reach for home industries. This research aims to produce prototypes that can be used by the home industry.

Previous study, has made a prototype using a static vacuum device, but this tool failed because water vapor filled the vacuum unit [4], therefore in this study it will be tried using a vacuum venturi.2.

\section{METHODS}

This research will be conducted in 3 (three) stages, namely:

a. Measurement of the initial performance of the prototype vacuum evaporator unit, this stage aims to get the tool reference setting, the nature of the resulting product, process pressure (ATM), temperature (Celsius), and process time (hour-minutes). 
b. The second test aims to get a good setting and improve experimental procedures, measured the same, namely the product produced, temperature (Celsius), process pressure (ATM), and processing time (timehour). From the results of this experiment, it was found that the recommendations for improving the vacuum evaporation device and experimental settings were obtained.

c. The third test simulates the direct production process using the recommended experimental setting from the second experiment. Here, the results of liquid palm sugar are compared between the first, second experimental products and products cooked in a pan.

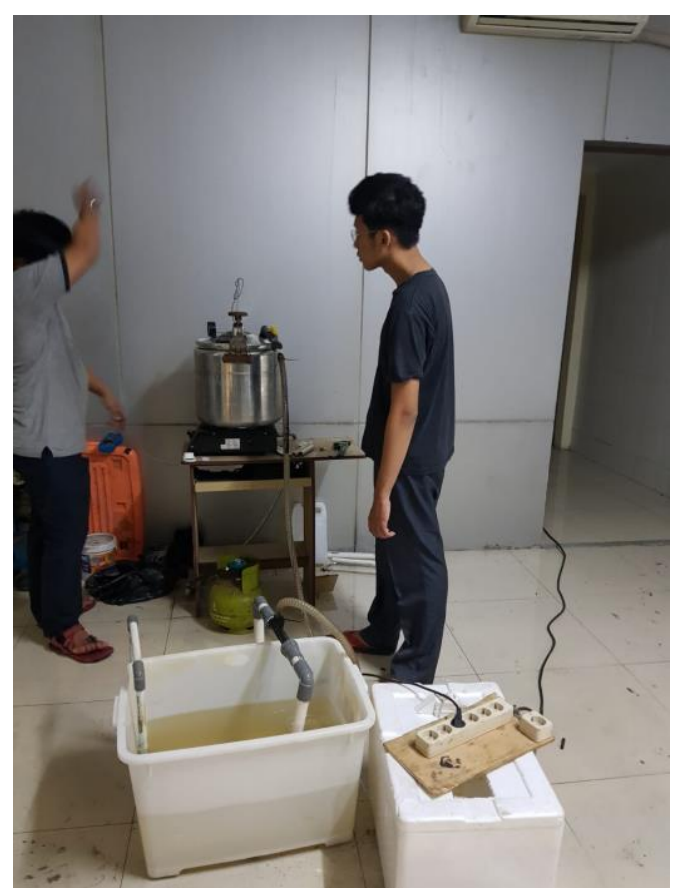

Figure 1. Vacuum evaporator unit

The data from this third test will be used to determine the performance and specifications of the vacuum evaporator unit being built and operating, and operating procedures will be developed.

\section{RESULTS AND DISCUSSION}

In the first test, the data that can be collected are: The weight of the sap water is $23.4 \mathrm{~kg}$, at a pressure of 0.32 ATM it boils at a temperature of $77 \mathrm{C}$. It is heated for up to 24 hours, causing the sap water to turn into caramel.

In the second test, it was set that the evaporation process was carried out for 9 hours, with a pressure of $0.32 \mathrm{ATM}$, and the temperature was raised to $80 \mathrm{C}$. The results obtained only reduced the water content by $26 \%$, concluding that the vacuum had to be re-paired. This experiment shows that increasing the temperature does not give significantly better results, so that the vacuum pressure will then be changed.

Changing the vacuum setting requires some improvements to the vacuum evaporator unit to reduce the potential for vacuum leaks. After repairing and adding a vacuum shield to the cable connections, bolts, and hose installation, a trial was carried out, and the vacuum pressure was found to reach 0.2 ATM.

Table 1. Second test result

\begin{tabular}{|c|c|c|c|c|c|}
\hline Time & height & $\%$ & $\begin{array}{c}\text { Weight } \\
(\mathrm{kg})\end{array}$ & Colour & $\begin{array}{c}\text { Brix } \\
\text { meter }\end{array}$ \\
\hline 10.00 & 13.5 & & 20.5 & $\begin{array}{c}\text { Yellow } \\
\text { pale }\end{array}$ & 20 \\
\hline 12.00 & 13 & 4 & 20.3 & Yellow & 20 \\
\hline 14.00 & 12.5 & 7 & 19.5 & Yellow & 25 \\
\hline 19.00 & 10 & 26 & 16.5 & Yellow & 28 \\
\hline
\end{tabular}

Then the third test was carried out. In this test, a test was carried out using a venturi with a di-ameter of 0.5 inches, but it turned out that the pump could not produce a discharge under the venturi to get vacuum pressure. So it was decided to use a 0.25 -inch diameter venturi. Some leaks were fixed for a better vacuum.

After the vacuum was repaired, this test also measured the use of LPG gas during the boiling of sap water. The vacuum pressure used in the third test is 0.24 ATM.

Table 2. Third test data

\begin{tabular}{|c|c|c|c|}
\hline Time & Height & $\%$ & Temperature \\
\hline 13.15 & 18.5 & 100 & 69 \\
\hline 15.00 & 16.5 & 89 & 73 \\
\hline 16.07 & 14.5 & 78 & 70 \\
\hline 16.57 & 13.5 & 73 & 69 \\
\hline 17.59 & 12.6 & 68 & 70 \\
\hline 19.20 & 10.2 & 55 & 70 \\
\hline 20.47 & 8.5 & 46 & 72 \\
\hline 22.55 & 3.8 & 21 & 72 \\
\hline
\end{tabular}

Within 9 hours 40 minutes, it reaches $21 \%$ water content, following the liquid sugar standard set by the draft Indonesian liquid sugar standard [5]. In energy use for 
production to reduce to $21 \%$ water content it consumes LPG about $(7.1 \mathrm{~kg}-5.9 \mathrm{~kg}=1.3 \mathrm{~kg})$.

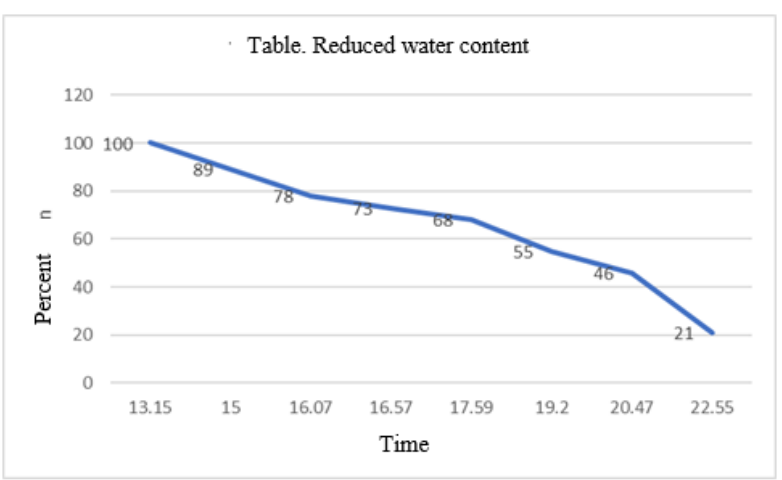

Figure 2. Water content of liquid palm sugar

Setting experiment for palm sugar syrup is similar to the setting for processing coconut sap to become sugar syrup [6], and this setup give a better result, its shown that this prototype that has been develop is have a good performance to produce sugar syrup.

A long heating time will cause an increase in the content of 5-hydroxymethyl furfural (HMF) which is carcinogenic [7], In research, the heating time has been successfully reduced from 24 hours to 9 hours 20 minutes. Improvements still need to be made so that the heating time can be shorter, because in addition to avoiding the increase in HMF content, it is also more economical. Design improvements can also be made by adding temperature control [8] so that the process temperature can be maintained according to what is needed.

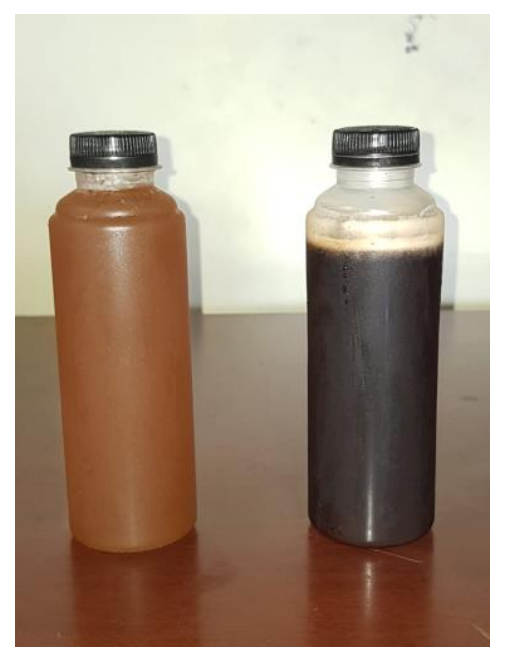

Figure 3. Physical comparison of sugar from vacuum evaporation (left) liquid sugar produced manually (right).

\section{CONCLUSION}

Tests have been carried out on a prototype vacuum evaporator and produce quality liquid palm sugar products in accordance with Indonesian liquid sugar standards. At a vacuum pressure of $240 \mathrm{~m}$-Bar and a boiling temperature of $70 \mathrm{oC}$ for 9 hours 20 minutes, this is similar to the setting for processing coconut sap to become sugar syrup [6]. The colour of the sugar syrup produced also shows that the production process produces less HMF compared to products using the long heating method at high temperatures.

\section{REFERENCES}

[1] E Listijorini and S Wiyono 2019 Rice husk gasification performance to decrease water content in liquid palm sugar IOP Conf. Ser.: Mater. Sci. Eng. 673 012121

[2] Jayanudin et all Phenolic 2019 Analysis and characterization of palm sugar (arenga pinnata) produced by the spray dryer Oriental Journal Of Chemistry 35 No.(1): Pg. 150-156

[3] Phisut Naknean 2013 Changes in properties of palm sugar syrup produced by an open pan and a vacuum evaporator during storage International Food Research Journal 20(5) 2323-34

[4] Listijorini, E. and S. Wiyono 2019 Rice husk gasification performance to decrease water content in liquid palm sugar IOP Conference Series: Materials Science and Engineering 673012121

[5] Badan Standardisasi Nasional [BSN] Gula Palma. SNI 01-3743-1995

[6] Muhammad T Asgharm 2020 Processing of coconut sap into sugar syrup using rotary evaporation, microwave, and open-heat evaporation techniques 100 4012-19

[7] Yosephine A. Djohan and Mutita Meenune 2021 Effect of heating conditions on physical and chemical characteristics of sugar syrup Asia - Pacific Journal of Science and Technology 26

[8] H. Aripin et al 2018 Automated temperature control with adjusting outlet valve of fuel in the process of cooking palm sugar IOP Conf. Ser: Mater. Sci. Eng. 336012018 